\title{
DIÁLOGO E DIALOGISMO EM MIKHAIL BAKHTIN E PAULO FREIRE: CONTRIBUIC̄ÕES PARA A EDUCAÇÃO A DISTÂNCIA
}

Fabio Scorsolini-Comin"

RESUMO: O objetivo deste estudo foi abordar as noções de diálogo e dialogismo nas obras de Mikhail Bakhtin e Paulo Freire, discutindo suas contribuições para o contexto da educação a distância (EAD). Foram apresentadas situações-problemas presentes nesses cursos, no que tange às ferramentas de interação e aprendizagem. As proposições dessas ferramentas devem ser redigidas de modo a convidar os participantes a se posicionarem, permitindo a assunção de diferentes vozes acerca do assunto. O dialogismo, ao relativizar a autoria individual, ajuda-nos a compreender o caráter coletivo dessas produções. Tais ferramentas podem ser um poderoso instrumento de uma educação que se propõe transformadora, como na EAD, não ocupando apenas o sentido de flexibilizar a aprendizagem para pessoas separadas geográfica e temporalmente. Essas ferramentas, ultrapassando o caráter avaliativo, podem e devem contribuir para a formação de profissionais dispostos ao diálogo e à construção de posicionamentos que considerem o outro e o contexto histórico e social envolvido.

Palavras-chave: Diálogo. Linguagem. Educação a distância.

* Doutor em Psicologia pela Universidade de São Paulo (USP) e Professor Adjunto do Departamento de Psicologia da Universidade Federal do Triângulo Mineiro (UFTM). E-mail: scorsolini_usp@yahoo.com.br 


\title{
DIALOGUE AND DIALOGISM ACCORDING TO MIKHAIL BAKHTIN AND PAULO FREIRE: DISTANCE EDUCATION CONTRIBUTIONS
}

\begin{abstract}
This study aim to discuss dialogue and dialogism notions referred to Mikhail Bakhtin and Paulo Freire works, by debating over contributions to the context of distance learning (EAD, in Portuguese). Problem-situations observed on distance courses were presented, concerning with interaction and learning tools. These tools propositions should be rewrite therefore to invite participants to adopt a posture, allowing them to assume different voices on the subject. The dialogism, by connecting to individual authorship, helps one to understand the collectivity nature of these productions. Such tools can be a powerful agent from an education program that has the intention to become revolutionary, as in EAD, occupying not only the sense of flexible learning for geographically and temporally separated people. To sum up, by surpassing the evaluative character, these instruments can and should contribute to professionals training who are willing to the dialog as well to build positions which consider the other (human being), historical and social involved context.
\end{abstract}

Keywords: Dialogue. Language. Distance education.

\section{ELDIÁLOGO YEL DIALOGISMOEN MIKHAIL BAKHTIN Y PAULOFREIRE: CONTRIBUCIONES A LA EDUCACIÓN A DISTANCIA}

RESUMEN: El objetivo de este estudio fue abordar las nociones de diálogo y dialogismo en las obras de Mikhail Bakhtin y Paulo Freire, discutiendo sus contribuciones al contexto de la educación a distancia (EAD). Se presentan situaciones problemáticas en cursos, en que se refieren a las herramientas de interacción y aprendizaje. Las proposiciones de estas herramientas deben ser redactadas con el fin de invitar a los participantes a tomar una posición, lo que permite la asunción de diferentes voces sobre el tema. El dialogismo, a relativizar los autores individuales, nos ayuda a comprender la naturaleza colectiva de estas producciones. Estas herramientas pueden ser poderosas para la educación que propone la transformación, como en EAD, ocupando no sólo el sentido de aprendizaje flexible para personas separadas geográficamente y temporalmente. Estas herramientas, superando el carácter evaluativo, pueden y deben contribuir a la formación de profesionales dispuestos a hablar y construir posiciones que consideran las otras personas y el contexto histórico y social en cuestión.

Palabras clave: El diálogo. El lenguaje. La educación a distancia. 


\section{INTRODUÇÃO}

"Alguém deve rever, escrever e assinar os autos do Passado antes que o Tempo passe tudo a raso”. (Cora Coralina, 1985)

Este estudo destaca como centro os pensamentos de dois autores que se tornaram importantes em diferentes disciplinas do conhecimento: Mikhail Bakhtin na Linguística e nos Estudos Literários, e Paulo Freire na Educação. No entanto, suas áreas primárias de estudo e de investigação ultrapassam essas margens, de modo que suas contribuições têm estabelecido diálogos com diversos campos, entre eles a Psicologia (CASTRO; PORTUGAL; JACÓ-VILELA, 2011) e a educação a distância (EAD) (BICALHO; OLIVEIRA, 2012; SCORSOLINI-COMIN; INOCENTE; MATIAS, 2009; SCORSOLINI-COMIN; SANTOS, 2010), esta última de particular interesse neste artigo.

Embora nenhum desses pensadores tenha trazido a EAD em suas reflexões, suas propostas abrem espaço para muitas discussões em torno dos processos interativos dialógicos mediados por tecnologias, de modo que trazer suas contribuições para o cenário atual dos estudos sobre educação pode oferecer uma compreensão nova acerca do que é interação e de como a linguagem pode exprimir muito mais do que aspectos fonológicos e sintáticos, pode revelar jogos de poderes, aspectos históricos, políticos, embates sociais e conflitos marcados na palavra em ação.

A aproximação entre as obras desses autores não é recente e demonstra de que modo as noções de diálogo existentes podem, efetivamente, contribuir para a compreensão dos processos de interação em ambientes virtuais de aprendizagem e de ensinoaprendizagem, problematizados para além de aquisições cognitivas ou de processamento de informações. Em uma compreensão radical da linguagem e da relação da língua com o contexto mais amplo - social, econômico, político, cultural e histórico - ambos os autores proporcionam leituras mais flexíveis e palatáveis para a compreensão de realidades em permanente transformação.

Para operacionalizar o diálogo neste artigo, apresentaremos as biografias e os principais aspectos das obras de Bakhtin (2010, 2012) e Freire (2006a, 2006b, 2010), em um primeiro momento. Posteriormente, as noções de diálogo, dialogismo e dialogicidade, exploradas por esses autores, serão priorizadas como condutoras da discussão de casos observados no contexto da educação a distância (situações-problema), em cursos de longa 
duração ofertados a distância. Desse modo, a partir do que foi exposto, o objetivo deste estudo é abordar as noções de diálogo e de dialogismo nas obras de Freire e Bakhtin, discutindo suas contribuições para o contexto da educação a distância.

\section{APRESENTANDO NOSSOS INTERLOCUTORES: BAKHTIN E FREIRE}

Mikhail Bakhtin, nascido em Oriol, Rússia, ao final do século XIX, é um dos autores mais expressivos na contemporaneidade, haja vista a recente penetração de sua obra no Ocidente, a partir da década de 1970. Filósofo e linguista, é um dos mais importantes pesquisadores da linguagem humana, sendo referido nas investigações sobre Literatura, História, Antropologia, Artes, Linguística, Arquitetura, Psicologia e Educação. Embora tenha sido uma figura participante nos debates sobre estética e literatura ocorridos na União Soviética na década de 1920, a relevância do seu pensamento só se tornou realidade por volta da década de 1960. Bakhtin investigou os romances e desenvolveu importantes conceitos como dialogismo, polifonia, cronotopo e carnavalização, hoje amplamente empregados e estudados em todo o mundo. Seus estudos foram desenvolvidos junto a um grupo de importantes estudiosos russos, conhecido como "Círculo de Bakhtin".

No Brasil, sua obra tem sido investigada por diferentes grupos de pesquisa ligados a diferentes universidades, como a Universidade Estadual de Campinas, Universidade de São Paulo, Universidade Federal do Paraná e Universidade Federal de São Carlos, onde se encontram importantes núcleos que congregam profissionais de diversas áreas, refletindo o caráter interdisciplinar da obra bakhtiniana. Anualmente, muitos congressos temáticos sobre Bakhtin são realizados. Entre eles, podemos destacar o "Colóquio Dialogismo: 100 anos de Bakhtin", organizado pelo Departamento de Linguística da Universidade de São Paulo, em 1995, um dos mais emblemáticos no contexto nacional. Ainda assim, devese destacar a dificuldade que a obra de Bakhtin teve de ser inserida em nosso país, devido principalmente aos problemas de tradução de seus livros do idioma russo. Conforme narra Schnaiderman (2005), um dos responsáveis pela introdução dos estudos de Bakhtin no Brasil, em 1964, as livrarias que comercializavam obras russas foram fechadas pelos militares, de modo que o acesso às suas obras era extremamente difícil. Na contemporaneidade, no entanto, Bakhtin tem se tornado uma referência cada vez mais presente nos currículos 
de diferentes cursos de graduação e pós-graduação, apesar do predomínio dos estudos literários e linguísticos.

Paulo Freire é um dos educadores brasileiros mais conhecidos e respeitados em todo o mundo, influenciando o movimento chamado pedagogia crítica. Nasceu em Recife no ano de 1921. Sua prática didática fundamentava-se na crença de que o educando assimilaria o objeto de estudo, fazendo uso de uma prática dialética com a realidade, em contraposição à chamada educação bancária (Freire, 2010), de caráter tecnicista e alienante. Em sua concepção de educação, o educando criaria sua própria educação, sendo autônomo para buscar seu próprio caminho e libertando-se de aspectos alienantes presentes na educação (FREIRE, 2006a, 2006b). Sua obra teve impacto importante na educação popular, voltada tanto para a alfabetização e escolarização como para a formação da consciência política. Desenvolveu um método de alfabetização dialético, rompendo com uma forte tradição mecanicista de alfabetização vigente à época. Em 2012, foi reconhecido como patrono da educação brasileira.

A educação mecanicista é chamada por Freire de "bancária", em contraposição à educação verdadeiramente formadora, a "libertadora". Em sua tentativa de definir o professor e a tarefa de docência, utiliza a especificação de um mestre dinâmico e envolvente, no mais profundo dos termos. O professor não pode se resumir ao narrador que conduz os educandos à memorização mecânica do conteúdo narrado. Os alunos não podem mais ser considerados depositários. Em sua concepção, a educação "bancária" quer calar seus alunos, quer fazê-los alienados e sem vontade própria. Nessa mesma linha, é somente o professor que ensina, ele já detém tudo o que é necessário, somente os alunos têm que aprender. O professor é que escolhe o que quer ensinar, sem jamais questionar se tudo aquilo faz sentido para os alunos, - e talvez para ele mesmo. Na educação tipicamente "bancária", o educador chega ao status de sujeito do processo, enquanto os educandos se tornam meros objetos (SOARES; VERÍSSIMO, 2010). E objetos se amoldam, adaptam-se ao mundo, jamais transformam, reinventam, superam. O professor tem de ser o carro-chefe dessa mudança por uma educação "libertadora", sendo sujeito agente do processo transformador. É por não haver papéis cristalizados que Freire chama os professores de educadores-educandos e os alunos de educandos-educadores, uma vez que, na relação pedagógica, ambos trocariam experiências e aprenderiam juntos, não delimitando papéis fixos e sem possibilidade de negociação. 


\section{DIALOGISMO OU DIALOGISMOS EM BAKHTIN}

Bakhtin é um dos autores que mais claramente contribuíram para os estudos acerca do diálogo e como ele pode ocupar uma posição de centralidade na vida humana. Ultrapassando os estudos interessados em uma compreensão estrutural de diálogo, esse autor propõe tal noção como produto histórico, marcado cultural e socialmente, fundamentando uma crítica ao mecanicismo positivista, à valorização do aspecto sistemático da proposta saussuriana e do estruturalismo subsequente. Também apresenta o diálogo como espaço de embates, lutas, assimetrias que refletem os próprios aspectos da interação social. O diálogo não seria uma instância apenas de negociação e de mediação de conflitos, mas um espaço no qual esses embates poderiam ser acolhidos e repensados, de modo a contribuir com a compreensão de uma realidade macro, a realidade social.

O diálogo, no sentido estrito do termo, não constitui, é claro, senão uma das formas, é verdade que das mais importantes, da interação verbal. Mas pode-se compreender a palavra "diálogo" num sentido amplo, isto é, não apenas como a comunicação em voz alta, de pessoas colocadas face a face, mas toda comunicação verbal, de qualquer tipo que seja. (Bakhtin, 2012, p. 117)

Essa primeira definição já abre diferentes possibilidades de significação do diálogo em movimento, rejeitando as noções tradicionais vigentes à época em que seus conhecimentos passaram a ser compartilhados pela comunidade científica. O diálogo não envolveria apenas o emissor ou o receptor da mensagem, mas as tendências básicas e constantes da recepção ativa do discurso de outrem, o que se mostra fundamental para a construção do diálogo. Essa recepção ativa não se trata apenas da compreensão da mensagem, mas também da incorporação do outro no diálogo, de modo que o outro passe a constituir o sujeito-emissor. A presença das palavras do outro nas palavras do eu é um dos primeiros elementos que caracterizam o conceito de dialogismo, que pressupõe o relativismo da autoria individual. Mesmo no diálogo interior, esses múltiplos outros participam ativamente, de modo que se opera a ilusão de que as palavras são produto dos atos de fala de um dado sujeito, o que, em Bakhtin, abre espaço para um sujeito-coletivo, produtor e recriador de práticas presentes no espaço discursivo.

Em Bakhtin, conforme apontado por Amorim (2012), a noção de dialógico ou de dialogicidade aparece sob diversas formas. Uma primeira forma é a do dialogismo como sendo um princípio interno da palavra, o que significa que, no discurso, o 
objeto está mergulhado de valores e definições, fazendo com que o falante se depare com múltiplos caminhos e vozes ao redor desse objeto (SCORSOLINI-COMIN; SANTOS, 2010). Uma segunda forma é a dialogicidade dos enunciados, que equivale a dizer que mesmo antes da concretização de um determinado enunciado - e também posteriormente, há outros enunciados, que vêm dos outros, aos quais o próprio enunciado está vinculado por algum tipo de relação. O próprio locutor seria um respondente, na medida em que ele não detém o discurso pela primeira vez, ou seja, o discurso não se origina nele, não é por este inaugurado. Ao selecionarmos uma determinada palavra, nós a tiramos de outros enunciados, polemizamos com eles de modo dialético e constante.

Uma terceira forma de dialogismo é aquele construído pela emergência de várias vozes relacionadas a um tema específico, dadas pela antecipação da resposta dos outros e das possíveis respostas imaginadas por ele, em função do interlocutor e do contexto. Por fim, destaca-se a dialogização das linguagens, na medida em que uma língua nacional é plural (com linguagens das reuniões sociais, familiar, cotidiana, sociopolítica; linguagem dos jargões profissionais; linguagem de geração e de idade; linguagem de autoridade; linguagens oratória, publicitária, científica, jornalística, literária, entre outras). Essa pluralidade manifesta-se a partir de múltiplas vozes que estabelecem uma variedade de ligações e inter-relacionamentos.

O discurso bakhtiniano, desse modo, é considerado vivo nos modos sociais, devendo ser visto sob formas contraditórias e como mundos de múltiplas linguagens que se interligam. Assim, como referido por Amorim (2012), essas diferentes linguagens não se excluem, mas interligam-se dialogicamente de maneiras diversas. Nesse processo, ocorre a coexistência de contradições socioideológicas entre o presente e o passado; entre diferentes épocas do passado; entre diferentes grupos socioideológicos do presente; entre tendências, escolas, círculos e assim por diante, com o encontro e a disputa entre pontos de vista sociolinguísticos distintos.

Bakhtin (2012) destaca a centralidade da linguagem na vida humana. A palavra é concebida como material da linguagem interior e da consciência, além de ser elemento privilegiado da comunicação na vida cotidiana, que acompanha toda a criação ideológica, estando presente em todos os atos de compreensão e de interpretação. Para esse autor, a palavra tem sempre um sentido ideológico ou vivencial, relaciona-se totalmente com o contexto e carrega um conjunto de significados que socialmente foram dados a ela. A palavra é também 
polissêmica e plural, uma presença viva da história, por conter múltiplos fios ideológicos que a tecem.

O produto do ato da fala, a enunciação, é de natureza social, determinada pela situação mais imediata ou pelo meio social mais amplo. E o que torna a compreensão de uma palavra possível é também aquilo que é presumido pelo ouvinte, porque toda a palavra usada na fala real possui um acento de valor ou apreciativo, transmitido por meio da entoação expressiva. Por isso, junto com a palavra, acontecem os gestos, as expressões faciais, a tonalidade e entonações que contribuem para que determinadas mensagens e inteligibilidades possam ser transmitidas e compartilhadas (SCORSOLINI-COMIN; AMORIM, 2010).

A palavra, na concepção bakhtiniana, permite a constituição do sujeito na e por meio da linguagem. Não se trata aqui de lidar com uma palavra enquanto unidade da língua, nem com a significação dessa palavra, mas sim com o enunciado acabado e com um sentido concreto, ou seja, seu conteúdo. A significação da palavra refere-se à realidade efetiva nas condições reais da comunicação verbal. Para Bakhtin (2010), a palavra seria considerada um signo social, funcionando como elemento essencial que acompanha e comenta todo ato ideológico.

\section{DIALOGICIDADE EM FREIRE: EDUCAÇÃO COMO PRÁTICA LIBERTADORA}

Para Freire (2010), o diálogo é um fenômeno humano constituído, essencialmente, pela palavra, que possui duas dimensões intimamente relacionadas: ação e reflexão. Em sua concepção, não existe palavra verdadeira que não seja práxis (ação reflexiva), de modo que a palavra se coloca a serviço de transformar o mundo. Ação e reflexão não são dimensões que podem ser compreendias de modo isolado ou priorizando uma em detrimento da outra, de modo que o diálogo só pode ser estabelecido quando ação e reflexão se colocam juntas e articuladas. É por esse motivo que, muitas vezes, Freire cunha a palavra ação-reflexão. Em sua concepção dialética, o diálogo configura o caminho pelo qual os homens ganham significação enquanto homens, ou seja, o diálogo é o elemento humanizador e transformador da realidade.

“(...) o diálogo é uma exigência existencial. E, se ele é o encontro em que se solidarizam o refletir e o agir de seus sujeitos endereçados ao mundo a ser transformado e humanizado, não pode reduzir-se a um ato de depositar ideias de um sujeito no outro, nem tampouco tornar-se simples troca de ideias a serem 
consumidas pelos permutantes. (...) É um ato de criação. Daí que não possa ser manhoso instrumento de que lance mão um sujeito para a conquista do outro. A conquista implícita no diálogo é a do mundo pelos sujeitos dialógicos, não a de um pelo outro" (Freire, 2010, p. 91).

Como podemos observar, o diálogo possui um propósito marcado socialmente, pois ele deve servir para a transformação do homem e para a sua libertação, e não como um instrumento que favoreça a dominação e a alienação da pessoa, submetida à outra. O diálogo é um instrumento de transformação social ao aproximar diferentes realidades e promover o reconhecimento do homem em seu semelhante, de modo a solidarizar-se com outrem e não estabelecer uma relação de dominação. A relação de cooperação deve ser priorizada como condutora do diálogo.

Assim, para que o diálogo possa ser estabelecido, é preciso que os homens reconheçam-se como iguais, possam partilhar sentimentos, expectativas e necessidades, em uma relação de simetria: "Como posso dialogar, se me admito como um homem diferente, virtuoso por herança, diante dos outros, meros 'isto', em que não reconheço outros eu?" (FREIRE, 2010, p. 93, grifos do autor). O reconhecimento do outro como igual não pressupõe o não reconhecimento da diversidade constitutiva dos seres humanos, mas a simetria em termos sociais que deve ser buscada. Essa condição retoma os próprios pressupostos da educação como prática de libertação, ou seja, de não negação das assimetrias. Se as assimetrias são negadas, excluem-se as relações entre dominadores e dominados, alienando as pessoas e dando a impressão de que tais relações são naturais. Para Freire (2010), o exercício deve ser de reconhecer os seres humanos como iguais, a despeito das relações que se apresentam, ou marcando concretamente que o diálogo deve ser um instrumento para o reconhecimento dos iguais e, nesse sentido, também para a libertação. A educação libertadora pode ser um poderoso instrumento para que esse diálogo verdadeiro seja buscado.

Freire não emprega a palavra dialogismo, tal como Bakhtin, mas sim dialogicidade. Ao destacar o termo desse modo, sugerese a impressão de diálogo em acontecimento, em constante ação-reflexão. A dialogicidade ultrapassa a consideração de uma característica da linguagem (como no caso do emprego do termo dialogismo) ou uma marca discursiva e passa a ser um instrumento social de humanização do ser humano, de combate às relações assimétricas, de libertação do homem das estruturas que o aprisionam e o alienam de suas próprias condições. 
Outra condição para o diálogo destacada por Freire (2010) é a de que haja o pensar verdadeiro, considerado por esse autor como um pensar crítico, um pensar que, "não aceitando a dicotomia mundohomens, reconhece entre eles uma inquebrantável solidariedade" (p. 95). As dicotomias eu-outro, mundo-homens, mente-corpo, individual-coletivo geram imprecisões e incorreções ao se abordar a busca pela transformação social. Essas dicotomias são responsáveis por afastar os homens de seus objetos de conhecimento, ou seja, os próprios homens. Quando destacam que o mundo está fora deles, esses mesmos homens não se implicam na tarefa de compreender como o homem está no mundo, atuando, modificando-o, podendo transformálo. O diálogo verdadeiramente freireano é aquele que ultrapassa essas dicotomias, compreendendo o homem como entidade responsável, crítica e problematizadora, capaz de promover o acontecimento do diálogo entre pessoas em desenvolvimento, ativamente implicadas na construção de seus processos sociais, históricos, culturais e políticos (FREIRE, 2006A; SOARES; VERÍSSIMO, 2010). A dialogicidade, como marca do homem considerado dialógico, constitui um exercício contra a prática antidialógica, alienante e dicotomizadora. A dialogicidade deve ser incorporada ao exercício de ser humano e de humanizar-se permanentemente.

\section{CONVERSAS SOBRE EDUCAC̣ÃO A DISTÂNCIA}

A seguir, serão trazidas e analisadas, com base nos estudos de Bakhtin e Freire, três situações de conflito enfrentadas por tutores em cursos de especialização ofertados na modalidade a distância, para gerentes e executivos do setor bancário e operacionalizados pelo Instituto de Ensino e Pesquisa em Administração (INEPAD) em parceria com instituições de ensino superior de todo o país. Trata-se de cursos de MBA (Master Business Administration) oferecidos in company, nos quais os alunos devem interagir a partir de diversas ferramentas de aprendizagem, como o Fórum de Discussão e o Painel de Opiniões (SCORSOLINI-COMIN, 2013). Na EAD, os tutores podem ser considerados os professores que estão mais diretamente relacionados aos alunos, uma vez que interagem diariamente a partir de diferentes ferramentas de aprendizagem e a partir de um processo de formação específica que envolve treinamentos na plataforma de aprendizagem. Em alguns cursos, os tutores podem desempenhar diferentes funções, como o acompanhamento dos alunos, atendimento a dúvidas, autoria de materiais, aulas por meio de videoconferências ou e-aulas, 
entre outros (BICALHO; OLIVEIRA, 2012). Nas situações trazidas a seguir, retiradas de cursos a distância ofertados pelo INEPAD, como os destacados por Scorsolini-Comin (2013), os tutores acompanham a aprendizagem dos alunos nas ferramentas de interação do curso. Os apontamentos aqui trazidos não refletem o funcionamento de um determinado curso apenas, mas pode balizar práticas e estratégias em diferentes situações de aprendizagem na modalidade a distância.

\section{Situação 1:}

No contexto de um curso de especialização na modalidade a distância, os alunos participam semanalmente de fóruns de discussão relacionados aos conteúdos aprendidos nas diferentes disciplinas que compõem o curso. O fórum se inicia com a postagem de um tutor acerca do conteúdo estudado. A partir dessa postagem disparadora, os alunos passam a discutir. No entanto, um tutor tem encontrado como dificuldade o fato de que os alunos apenas concordam com uma postagem anterior, não apresentando os seus argumentos. Por vezes, escrevem apenas "concordo" ou "muito bom o comentário". Como o tutor pode agir para fomentar a discussão em um ambiente virtual de aprendizagem?

Os fóruns de discussão são espaços privilegiados de interação nos ambientes virtuais. Embora existam diferentes tipos e estruturas de fóruns, geralmente eles são organizados a partir de uma proposição inicial com a função de convidar os alunos para a discussão (Bicalho; Oliveira, 2012; Scorsolini-Comin; Matias; Inocente, 2009). Essa proposição geralmente apresenta uma situação que convida o aluno para o debate e para a emissão de um posicionamento a respeito, respaldado nos conteúdos aprendidos no curso. Muitos fóruns de discussão, no entanto, não geram discussões por parte de seus alunos, uma vez que são organizados em forma de uma pergunta, geralmente contendo apenas uma resposta certa. Nesses casos, o debate termina assim que um aluno oferece a resposta certa, fazendo com que os demais participantes apenas concordem com a resposta correta.

Os cursos na modalidade a distância oferecem diferentes reforçamentos para a participação no fórum, como a pontuação por presença (exemplo: escrever "concordo" já contabiliza a participação) ou uma nota avaliativa sobre o conteúdo do que foi escrito (geralmente atribuída pelo tutor). Independentemente da forma como se organiza o processo avaliativo nos diferentes cursos, um ponto central é a formulação da proposição. Além de ser redigida de modo a efetivamente convidar o participante a se 
posicionar, a emitir uma resposta, deve permitir a assunção de diferentes posicionamentos e vozes acerca do assunto, ou seja, deve propiciar o discurso dialógico, em contraposição ao monológico, que permite apenas uma voz e apenas um sentido, ou seja reforçando o dualismo "certo" e "errado". Esse discurso dialógico, no entanto, ultrapassa a necessidade de um outro na constituição dos discursos e incorpora um "olhar compreensivo e abrangente dos processos históricos, fundamentalmente porque implica conceber a produção discursiva como um vasto e complexo universo de interações orientadas sócio-historicamente" (CASTRO; PORTUGAL; JACÓVILELA, 2011, p. 96), ou seja, que recupera não apenas os aspectos individuais e coletivos de uma dada produção, mas as diversas interações sociais e culturais em um dado contexto histórico que se cravam nos discursos, permitindo a circulação de determinados sentidos e a construção de determinadas significações.

Assim, a proposição disparadora deve assumir diferentes possibilidades de resposta ou diferentes saídas para o problema, de modo que cada aluno possa não apenas construir suas estratégias com base nos conteúdos estudados, mas também refletir junto com os demais alunos. O fórum não deve ser um espaço de concorrência (quem tem a melhor estratégia de solução), mas de embate (que pode deflagrar diferentes modos de resolução de um dado problema), de colaboração, de construção conjunta. Essa construção coletiva deve sempre se remeter ao contexto de produção e aos elementos vigentes que sustentam a emissão de pareceres, opiniões e permitem a discussão sobre determinados elementos ou pontos de vista.

O conceito de dialogismo, ao relativizar a autoria individual dos discursos, ajuda-nos a compreender o caráter coletivo das produções de um fórum, haja vista que os discursos não pertencem a um ou outro aluno, mas estão disponíveis a todos, de modo que o que cada um opera é, na verdade, um posicionamento diante da discussão. Esses posicionamentos não precisam estar em acordo, mas justamente em embate constante, refletindo a própria história da construção da linguagem, que não é isenta nem conduz à monossemia. Assim, o fórum pode fomentar, a partir da mediação do tutor, os espaços inacabados, as estruturas ainda em formação, os elementos de concordância e discordância entre os posicionamentos assumidos pelos estudantes. Esses embates também revelam a natureza social, política, cultural e histórica da linguagem, uma vez que os posicionamentos ditos individuais refletem a história de um sujeito da linguagem, com uma dada 
história, com determinados repertórios, entre outras características, atualizadas por meio de uma mensagem.

O tutor, ao mediar esse diálogo, pode favorecer que os alunos efetivamente assumam esses diferentes posicionamentos, sendo que esse embate pode se mostrar mais rico para a aprendizagem de determinados conteúdos do que a simples emissão de uma resposta avaliada como correta. Tornar o fórum um espaço que não busque as respostas corretas, mas o amadurecimento de posicionamentos é uma forma de incentivar a formação de sujeitos que possam dialogar com as diferenças, considerando a importância do contexto e a necessidade do outro para a construção do próprio posicionamento individual. Não se trata, pois, de um espaço para a emissão de opiniões, mas de diálogo entre pessoas diferentes para a construção de posicionamentos que reflitam um trabalho coletivo, contextualizado e atento aos aspectos sociais, culturais e históricos envolvidos.

\section{Situação 2:}

No mesmo curso de especialização a distância, os alunos participam de uma ferramenta chamada Painel de Opiniões. No primeiro dia da semana, eles são convidados a emitir um comentário/opinião sobre determinado assunto relacionado ao conteúdo estudado. Essa opinião é enviada individualmente e de modo anônimo. No segundo dia, cada aluno recebe alguns comentários de seus colegas de curso (não identificados), a fim de que possa avaliá-los, atribuindo-lhes uma nota, também de modo anônimo. No terceiro dia, os alunos recebem as notas enviadas pelos demais alunos acerca da sua opinião, postada no primeiro dia. Um problema encontrado é que os alunos geralmente têm atribuído avaliações muito altas (geralmente nota 10), uma vez que estão avaliando colegas de turma. Como o tutor pode agir a fim de potencializar os aspectos de aprendizagem dessa ferramenta?

Novamente, a estrutura didática e avaliativa do curso é um aspecto muito importante quando se analisa a efetividade de uma dada ferramenta, ou seja, se ela está atendendo aos objetivos da sua criação. Mais do que uma ferramenta responsável por gerar ou atribuir uma nota para os alunos, ela possui uma intencionalidade didática que deve ser analisada constantemente. O Painel de Opiniões é uma ferramenta que merece destaque, uma vez que faz com que o aluno se posicione de dois modos distintos acerca de um mesmo fato: como aluno, que emite a sua opinião a respeito 
de um fato e, posteriormente, como avaliador, analisando a opinião ou o posicionamento assumido por um colega de curso. Nesse processo avaliativo, pesam não apenas os seus conhecimentos sobre o assunto, mas também a comparação da opinião avaliada com o posicionamento já enviado no dia anterior pelo aluno-avaliador. Essa comparação é também uma fase do aprendizado, pois o aluno precisa reconhecer possibilidades de posicionamentos distintos do seu diante de um mesmo tema, elegendo qual opinião seria a mais adequada para cada caso. Não há respostas certas ou erradas, o exercício é reposicionar-se a partir das opiniões de outros alunos, abarcando outros elementos no processo avaliativo.

A pressão ou a preocupação com a nota (conceito na atividade) pode direcionar os alunos apenas para a questão da contabilização da atividade. Um acordo invisível pode existir entre os alunos, de modo que todos se atribuam notas altas. No entanto, o curso deve ser organizado de modo a não destacar o critério nota como o principal, mas sim o modo como o posicionamento foi construído, justificado, historicizado. A ferramenta deve ser apresentada aos alunos como um convite para que diferentes vozes possam emergir, tocando-se, mesclando-se, modificando-se, aperfeiçoando-se. Se não existem posicionamentos corretos ou incorretos, mas mais coerentes ou incoerentes a depender do ponto de vista adotado, esses diferentes discursos devem vir à baila como potencialidades de instalação de novas opiniões e discursos. Abre-se a necessidade não de valoração individual das opiniões, mas do foco nos possíveis reposicionamentos operados. Assim como afirmado em relação ao fórum, a proposição inicial pode ser expressa em formato de uma situação-problema, admitindo diferentes possibilidades de resolução, com diferentes saídas e aberturas.

As contribuições de Freire (2010) nos ajudam a compreender os posicionamentos assumidos pelos educandos-educadores, como se, em um primeiro momento, devessem se comportar mais como educandos e, posteriormente, como educadores. Um problema dessa concepção é a de dicotomização, no sentido de que pode emitir um comentário quem está aprendendo e pode avaliar a legitimidade dessa opinião quem está ensinando. $\mathrm{Na}$ educação como prática de liberdade, não poderíamos separar essas duas instâncias vivenciadas pelo sujeito, pois este seria sempre um educando-educador, ou seja, aquele que está em uma posição de que deve aprender, mas que também possui conhecimentos e bagagens que podem ser compartilhadas, destacando-se como aquele que educa, o educador. Para Freire, esses dois posicionamentos seriam assumidos por um mesmo sujeito, 
que é o sujeito da aprendizagem não no sentido de ser assujeitado, mas de ser descrito como aquele que aprende, que está envolvido com o conhecimento. $\mathrm{Na}$ situação-problema, isso equivale a dizer que quem opina e julga a opinião dos demais colegas é o mesmo educando-educador, de modo que ele pode compreender que, para emitir um parecer ou um julgamento sobre a opinião de um de seus pares, ele deve posicionar-se justamente como educando-educador.

Se assumirmos que as duas fases do painel de opiniões nada mais são do que instâncias nas quais as pessoas aprendem, essa cisão entre os papéis poderá deixar de existir e, com isso, os alunos não realizarão a atividade de modo a favorecer o grupo, mas sim a aprendizagem. Ao deslocar-se da posição educando-educador, o aluno passa a ver a ferramenta como a mantenedora de uma estrutura que a educação libertadora se põe a combater. Isso não significa que, na concepção freireana, a ferramenta deveria deixar de existir no curso, mas, ao contrário, deveria ser empregada para romper com as dicotomias, aproximando o aluno do processo avaliativo e compreendendo a avaliação como potencializadora da aprendizagem e como possibilidade de exercício democrático e libertador.

Desse modo, a ferramenta pode ser utilizada para favorecer uma avaliação que, de fato, contribua para a transformação dos estudantes no processo de aprendizagem, ou seja, que essas opiniões possam dialogar com o avaliador de modo dinâmico e sem um caráter de "certo" ou "errado", ou "bom" ou "ruim", mas de possibilidades de abertura de diálogo sobre temas específicos. A avaliação da opinião não precisa cotejar apenas o conteúdo da resposta, necessariamente, mas pode trazer à baila a construção da argumentação do aluno, a reflexão a partir de diferentes pontos de vista ou mesmo uma resposta que se abra a outros sentidos e possibilidades de leitura, compreensão e apropriação. Quando os alunos superam a visão avaliativa focada na emissão de uma nota, podem, de fato, empregar a ferramenta como um suporte na aprendizagem e no fomento ao diálogo.

Quando convocamos Bakhtin para essa conversa, uma das formas de potencializar a discussão e a reflexão na situação 2 seria que o aluno não apenas atribuísse uma nota arbitrária para os colegas, mas que pudesse comentá-la não para justificar o seu conceito, mas para proporcionar a continuidade dessa reflexão. A nota seria apenas um marcador das regras do curso, necessária para a organização do sistema de ensino, mas não delimitaria as participações e opiniões expressas. Esses aspectos podem ser comentados pelos tutores em feedbacks periódicos para as turmas, buscando um aproveitamento mais oportuno da ferramenta. 


\section{Situação 3:}

Ao final de cada disciplina, os alunos do curso de especialização na modalidade a distância precisam responder a uma prova dissertativa a distância. A prova fica disponível aos alunos por dois dias (geralmente um final de semana) em ambiente virtual. Os alunos respondem às perguntas em um editor de texto e enviam as respostas, que são corrigidas pelos tutores. Um problema apontado pelos tutores é que as respostas geralmente estão muito parecidas com os textos disponibilizados nas apostilas e livros do curso, de modo que os alunos parecem estar muito ligados aos textos, explorando pouco a assunção de sua autoria ou das suas próprias reflexões. Como os tutores podem ajudar os alunos no desenvolvimento da autoria?

Muitos teóricos da análise do discurso afirmam que a autoria não é um processo individual e isolado, mas justamente coletivo, uma vez que diferentes vozes se fazem presentes em nosso espaço discursivo, sendo atualizadas no momento da escrita (ORLANDI, 1996; PACÍFICO, 2002; PACÍFICO; ROMANO, 2011; PÊCHEUX, 1995). Essa também é uma das características fundamentais do dialogismo bakhtiniano, que coloca em xeque a autoria individual ao propor uma compreensão coletiva de produção discursiva, ainda que operada por uma só pessoa, no caso de uma prova nesses moldes da situação 3. A aparente cisão com as palavras dos autores do texto pode revelar a legitimação dessa linguagem como a mais adequada ou a mais esperada e reforçada pela equipe de tutores. Essa legitimação do discurso científico ou de um modo mais correto de expressar as opiniões reflete uma tendência tradicional de ensino bancário (FREIRE, 2010), que coloca o professor em uma posição de maissaber e o aluno na de não-saber, de modo que a escola (ou um curso ou qualquer programa de ensino) seria uma forma de disciplinar o não-saber por meio de uma estrutura assimétrica, hierarquizada. Quando os sistemas de ensino estão organizados desse modo, abre-se pouco ou nenhum espaço para a assunção de formas alternativas de compreensão e expressão de conhecimentos. Busca-se a construção de uma forma que possa conter os sentidos, em uma reversibilidade que tende a zero, caracterizando o discurso autoritário (PÊCHEUX, 1995). Assim, a educação não se torna uma prática de liberdade no sentido freireano, mas de aprisionamento e de ilusão de controle.

No enunciado da prova, os tutores podem explicitar diretamente que não será valorada a resposta mais semelhante ao texto base, mas que justamente os alunos deverão se abrir 
às possibilidades de reflexão a partir de suas práticas. Solicitar exemplos do cotidiano, não formular perguntas fechadas e com pouca abertura a outros posicionamentos, convidar os alunos para uma reflexão são estratégias que podem ser conduzidas no processo de fomentar a assunção da autoria. No entanto, a autoria não se trata de um produto mecânico ligado ao eu, mas um processo complexo que destaca o caráter coletivo da produção dos discursos. Mais do que cuidar do modo como os convites são feitos e a quem eles são endereçados na construção dos enunciados de provas, há que se recuperar a necessidade de que os próprios tutores entendam a funcionalidade da avaliação.

De algum modo, a prática docente tradicional acaba por reforçar as respostas mais parecidas com a realidade, de modo que muitos tutores não apenas são produto dessa forma de educar, como balizam suas intervenções amparados nessas considerações. Ainda que o exercício seja o de não cindir, o de não dicotomizar, somos produtos desse pensamento dicotômico, de modo que o embate deve ser constante, buscando, na educação, a possibilidade de libertação, de uma liberdade verdadeira como nos apresenta Paulo Freire, ou seja, aquela que não aceita as relações de dominação, mas as de cooperação, democracia e de solidariedade. Os tutores devem lançar-se no exercício de ajudar os alunos a se libertarem não do discurso científico, mas de legitimarem novas formas de ser e de estar na educação, na sociedade, em dado momento histórico. Essa prática, por vezes considerada utópica, acaba legitimando a continuidade do tradicional, que forma educandos que não conseguem se imaginar como educadores, que não conseguem legitimar seus discursos, que não podem assumir-se autores. Assim, a história é contada por outrem, pelos livros, por quem está de fora, alienando o educando, expatriando-o de sua própria relação com o saber.

É o que acontece nessa avaliação mostrada na situação 3: valoriza-se o saber que vem de fora do educando, de modo que ele não consegue se colocar na posição daquele que também pode emitir sua opinião, posicionar-se claramente, permitir que a sua palavra seja ação-reflexão (FREIRE, 2010). A mudança nesse cenário é gradual e deve ser fomentada pelos tutores ao redigirem os enunciados das questões - quando a mudança começa pelos tutores, os mesmos enunciados passam a refletir esse novo modo de relação com o saber, passando a convidar as múltiplas vozes e a compreendê-las como constitutivas, vendo, na diversidade e na multiplicidade, uma possibilidade de construção da autoria. $\mathrm{Na}$ EAD, muitas vezes, o 
foco dos questionamentos ou das intervenções recai sobre os alunos, desconsiderando a importância e o caráter multiplicador dos tutores, que também devem ser compreendidos como educadores-educandos.

Ainda em relação a essa questão, é importante mencionar o modo como a autoria tem sido apresentada na contemporaneidade, com a disponibilização de materiais, livros, artigos e diversas fontes de informação na rede mundial de computadores e de modo gratuito. Esse acesso permite que alunos e professores entrem em contato com uma vasta produção, o que agiliza o processo de recuperação de informações e disponibiliza ao educando uma série de conhecimentos, antes exclusivamente impressos, o que constitui uma inovação em termos informacionais. Essa facilidade na recuperação de conteúdos e informações, no entanto, tem propiciado práticas cada vez mais comuns no que se refere à construção da autoria, que é a ocorrência do plágio, facilitado pelo amplo acesso a uma infinidade de materiais. Os famosos verbos "copiar" e "colar" têm sido assimilados por muitos estudantes dessa nova geração como um sinônimo de busca, de pesquisa e de aquisição de conhecimentos, quando, na verdade, refletem apenas um processo de cópia e de apropriação indevida das ideias e palavras de outrem. Em que pesem as situações de plágio comprovado, que envolvem a cópia literal e sem qualquer referência de trechos e partes completas de obras já publicadas, há que se discutir a assunção da autoria na era digital. Não basta criar mecanismos de controle de autoria e verificação de plágio, mas de construir, junto aos estudantes, uma cultura na qual eles possam se ver e se perceber como autores, recuperando sim os discursos coletivos disponíveis no espaço discursivo, tal como proposto por Bakhtin (2010), e que possam também imprimir a própria argumentação diante do que já foi produzido, veiculado e conhecido.

Em uma era cujas facilidades tecnológicas convidam os educandos a apenas "acessar" conteúdos em busca de respostas prontas, tidas como "corretas" ou localizadas em artigos, livros e demais materiais considerados científicos, faz-se necessária uma educação que possibilite a adequada apropriação desses saberes, a fim de que os próprios estudantes possam se posicionar diante do já-dito. Assim, podem ser convidados a construir não discursos totalmente inéditos (haja vista a relativização da autoria individual anunciada por Bakhtin em seu princípio dialógico), mas que dialoguem com a produção existente e promovam rupturas, inovações e novos arranjos. As novas "condições sociais de autoria" (CASTRO; PORTUGAL; JACÓ-VILELA, 2011, p. 95) requerem a assunção de mecanismos 
de regulação de quem pode ser o autor, de quem escreve, de quem revisa e de quem pode ser considerado "autor" de determinado artigo, dizer, proposta ou ideia. Muitos desses questionamentos ainda estão em florescimento, mas podem e devem ser, cada vez mais, alvo de reflexões por parte de pesquisadores, educadores e profissionais relacionados ao universo da EAD.

\section{CONSIDERAC̣ÕES FINAIS}

Ao final desse percurso pelos pensamentos de Bakhtin e Freire e por algumas das problemáticas enfrentadas em cursos realizados na modalidade a distância, pode-se aproximar as propostas desses autores a fim de compreender que o diálogo inaugura diferentes possibilidades de interação em ferramentas de aprendizagem. Assim como a linguagem não é neutra, os mecanismos que operam essas ferramentas revelam muitas das concepções de educação vigentes, ainda que a EAD seja considerada um formato relativamente novo e alternativo por muitos autores. O diálogo verdadeiro, simétrico, solidário e cooperativo perseguido por Freire ainda parece distante desses modelos, ainda que algumas ferramentas possam ser utilizadas para construir relações menos assimétricas e dicotomizadas. O dialogismo bakhtiniano, ao deslocar a responsabilidade do dizer para o coletivo, em contraposição ao individual, põe em destaque a organização do curso, a formação dos tutores, os desenhos dos conteúdos e dos formatos de interação como marcadores de um modo de ser em sociedade, como um modo de formar alunos que sejam produto dessas concepções. O curso deixa de ser um depositário de uma formação específica em gestão de negócios, por exemplo, e passa a ser o reflexo de um dado momento histórico, de concepções de ser humano, de dominação, de poder, de possibilidade de transformação da realidade vigente.

As ferramentas de aprendizagem podem ser um poderoso instrumento de uma educação que se propõe transformadora, que se propõe diferenciada, como no caso da EAD, não ocupando apenas o sentido de flexibilizar a aprendizagem e proporcionar que pessoas separadas geográfica e temporalmente possam ter acesso às formações necessárias, como no caso dos executivos que atuam no setor bancário. Essas ferramentas podem e devem contribuir para a formação de profissionais dispostos ao diálogo, ao embate, à construção de posicionamentos que considerem o outro e o contexto 
histórico e social envolvido. Para tanto, os gestores educacionais, juntamente com os educandos-educadores e com os educadoreseducandos, devem refletir sobre o aluno que se deseja formar, sobre o aluno que se deseja em constante formação.

Uma limitação deste estudo é que Bakhtin e Freire não viveram sob a égide da era digital e não discorreram sobre esse cenário, de modo que a leitura de EAD que propusemos trata-se de uma tentativa de aproximação, haja vista que destacamos uma relação não presencial entre professores e alunos, em um contexto que coteja o fascínio tecnológico. Seria possível falar em dialogismo bakhtiniano ou na dialogicidade freireana na EAD? Certamente que muitos conceitos como a educação bancária e produtivista encontram respaldo em muitas propostas educacionais contemporâneas, como em cursos na modalidade a distância. No entanto, as situações elencadas neste estudo mostram um exercício, visando fomentar o diálogo, ainda que os interlocutores estejam separados no tempo e no espaço, ou seja, a comunicação não é síncrona.

Esse diálogo, no entanto, nem sempre é possibilitado pela ferramenta de interação apenas, mas pelo olhar do tutor, o educadoreducando, que pode utilizar a plataforma de aprendizagem e suas funcionalidades para fomentar o debate, a discussão, a construção e a desconstrução de saberes e posicionamentos, o que pode ser resumido no processo de aprendizagem, objetivo final de qualquer modalidade de ensino. Assim, a mediação pelo ser humano ainda é essencial não apenas no processo de ensino-aprendizagem, mas também no modo como interpretamos, conhecemos e promovemos mudanças no mundo. Recuperamos, desse modo, uma das afirmações de Bakhtin acerca da necessidade do outro em nosso desenvolvimento: “Tudo é meio, o diálogo é o fim. Uma só voz nada termina e nada resolve. Duas vozes são o mínimo de vida, o mínimo de existência” (1997, p. 257).

O diálogo aqui iniciado ainda deve ser fomentado, debatido, rebatido, problematizado a partir das contribuições não apenas de outros autores, mas também de outras situações observadas em cursos a distância. Mais do que oferecer respostas ou soluções para esses embates no campo prático, o presente artigo buscou refletir como os conceitos desses dois teóricos - Bakhtin e Freire - poderiam contribuir para desvelar sentidos e oferecer explicações alternativas para questões pedagógicas que não podem ser pensadas apenas em termos de estratégias didáticas como mudar a forma de redigir o enunciado de uma dada pergunta. Os enunciados não se 
esgotam nessas proposições e apontam para estruturas que nos constituem, que embasam nossa organização social, nossas escolas, nossos cursos presenciais e a distância.

Ter em mente esses aspectos descortina a solução automática para os problemas vivenciados na educação contemporânea, apresentando questões que devem disparar um diálogo permanente e em constante transformação. Outras reflexões mostram-se prementes, a fim de que essas dificuldades não sejam naturalizadas, mas possam instalar posicionamentos que levem em conta o contexto e a materialidade dos aspectos culturais, sociais, políticos e históricos, como apregoado por Bakhtin e Freire.

\section{REFERÊNCIAS}

AMORIM, K. S. Linguagem, comunicação e significação em bebês. Tese de Livre Docência nãopublicada, Faculdade de Filosofia, Ciências e Letras de Ribeirão Preto, Universidade de São Paulo, Ribeirão Preto, 2012.

BAKHTIN, M. M. Problemas da poética de Dostoievski. Trad. P. Bezerra. Rio de Janeiro: Forense Universitária, 1997.

BAKHTIN, M. M. Estética da criação verbal. 5. ed. Trad. P. Bezerra. São Paulo: Martins Fontes, 2010.

BAKHTIN, M. (Volochínov). Marxismo e filosofia da linguagem.13. ed. Trad. M. Lahud; Y. F. Vieira. São Paulo: Hucitec, 2012.

BICALHO, R. N. M.; OLIVEIRA, M. C. S. L. O processo dialógico de construção do conhecimento em fóruns de discussão. Interface: Comunicação, Saúde, Educação, 16 (41), 469483, 2012.

BRAIT, B. (Org.). Bakhtin: Dialogismo e construção do sentido. 2. ed. Campinas : Editora da Unicamp, 2005.

CASTRO, A. C.; PORTUGAL, F. T.; JACÓ-VILELA, A. M. Proposição bakhtiniana para análise da produção em Psicologia. Psicologia em Estudo (Maringá), 16(1), 91-99, 2011.

CORALINA, C. Poemas dos becos de Goiás e estórias mais. 18. ed. São Paulo: Global, 1985.

FREIRE, P. Conscientização: Teoria e prática da libertação. 3. a ed. São Paulo: Centauro, 2006a.

FREIRE, P. Pedagogia da autonomia. 34. ed. São Paulo: Paz e Terra, 2006b.

FREIRE, P. Pedagogia do oprimido. 49. ed. Rio de Janeiro: Paz e Terra, 2010.

ORLANDI, E. P. A linguagem e seu funcionamento: As formas do discurso. 4. ed. Campinas: Pontes, 1996.

PACÍfICO, S. M. R. Argumentação e autoria: O silenciamento do dizer. Tese de Doutorado nãopublicada, Faculdade de Filosofia, Ciências e Letras de Ribeirão Preto, Universidade de São Paulo, Ribeirão Preto, 2002.

PACÍFICO, S. M. R.; ROMÃO, L. M. S. Letramento, autoria e interpretação: A propósito de uma competição. Linguasagem, 16, 2011. Recuperado em 18 ago. 2012 de < http:/ / www.letras. ufscar.br/linguasagem/edicao16/art_002.pdf >.

PÊCHEUX, M. Semântica e discurso: Uma crítica à afirmação do óbvio. (E. P. Orlandi, Trad.). Campinas, SP: Editora da Unicamp, 1995. 
SCHNAIDERMAN, B. Bakhtin 40 graus (Uma experiência brasileira). In: BRAIT, B. (Org.). Bakhtin: Dialogismo e construção do sentido. 2. ed. Campinas: Editora da Unicamp, 2005.

SCORSOLINI-COMIN, F. Avaliação dos processos de ensino-aprendizagem em ações educacionais ofertadas a distância. Temas em Psicologia, 21(2), 335-346, 2013.

SCORSOLINI-COMIN, F.; AMORIM, K. S. "Em meu gesto existe o teu gesto": Corporeidade na inclusão de crianças deficientes. Psicologia: Reflexão e Crítica, 23(2), 261-269, 2010.

SCORSOLINI-COMIN, F.; INOCENTE, D. F.; MATIAS, A. B. Análise de ferramentas de interação e comunicação em ambiente virtual de aprendizagem a partir de contribuições de Bakhtin. Educação: Teoria e Prática, 19(32), 173-189, 2009.

SCORSOLINI-COMIN, F; SANTOS, M. A. Bakhtin e os processos de desenvolvimento humano: Um diálogo de, no mínimo, duas vozes. Revista Brasileira de Crescimento e Desenvolvimento Humano, 20(3), 805-817, 2010.

SOARES, L. L. M.; VERÍSSIMO. A formação do aluno na graduação em Psicologia pela Pedagogia de Paulo Freire. Psicologia: Ciência e Profissão, 30(3), 588-603, 2010.

Recebido: $15 / 01 / 2013$

Aprovado: 25/06/2014

Contato:

Universidade Federal do Triângulo Mineiro Departamento de Psicologia Avenida Getúlio Guaritá, 159, $3^{\circ}$ andar - Abadia Uberaba | MG | Brasil CEP 38.025440 